\title{
PENGARUH HUMAN RELATION, DISIPLIN, DAN MOTIVASI TERHADAP KEPUASAN KERJA KARYAWAN PADA PT. ORCHID BOGA UTAMA
}

\author{
Ketut Melinda Sari ${ }^{1}$ \\ I Gede Putu Kawiana ${ }^{2}$ \\ ${ }^{1,2}$ Fakultas Ekonomi, Bisnis, dan Pariwisata Universitas Hindu Indonesia \\ Email : melindasari1803@gmail.com
}

\begin{abstract}
An employee's positive attitude towards work can be seen from the level of job satisfaction of the employee. There are many factors that can affect job satisfaction including human relations, work discipline, and motivation. This research was conducted at PT. Orchid Boga Utama with the aim of knowing the effect of human relations, discipline, and motivation on employee job satisfaction either partially or simultaneously. The sample in this study were 75 respondents with a saturated sample method. Data collection was carried out through observation, interviews, questionnaires, literature study and documentation. The data analysis techniques used were validity and reliability tests, classical assumption tests, multiple linear regression analysis, determination, $t$ test (partial regression), and $F$ test (simultaneous regression). The results of this study are human relations have a positive and significant effect on job satisfaction, discipline has a positive and significant effect on employee job satisfaction, and work motivation has a positive and significant effect on employee job satisfaction, and human relations, discipline and work motivation have a positive and significant effect on satisfaction. employee work at PT. Orchid Boga Utama.
\end{abstract}

Keywords: human relations, discipline, motivation.

\begin{abstract}
ABSTRAK
Sikap positif seorang karyawan terhadap pekerjaan dapat dilihat dari tingkat kepuasan kerja karyawan tersebut. Terdapat banyak faktor yang dapat mempengaruhi kepuasan kerja di antaranya human relation, displin kerja, dan motivasi. Penelitian ini dilakukan di PT. Orchid Boga Utama dengan tujuan mengetahui pengaruhhuman relation, disiplin, dan motivasi terhadap kepuasan kerja karyawan baik secara parsial maupun simultan. Sampel dalam penelitian ini adalah sebanyak 75 responden dengan metode sampel jenuh. Pengumpulan data dilakukan melalui observasi, wawancara, kuesioner, studi pustaka dan dokumentasi. Teknik analisis data yang digunakan adalah uji validitas dan reliabilitas, uji asumsi klasik, analisis regresi linier berganda, determinasi, uji t (regresi parsial), dan uji $\mathrm{F}$ (regresi simultan). Hasil penelitian ini adalah human relation berpengaruh positif dan signifikan terhadap kepuasan kerja, disiplin berpengaruh positif dan signifikan terhadap kepuasan kerja karyawan, dan motivasi kerja berpengaruh positif dan signifikan terhadap kepuasan kerja karyawan, serta human relation, disiplin dan motivasi kerja berpengaruh positif dan signifikan terhadap kepuasan kerja karyawan pada PT. Orchid Boga Utama.
\end{abstract}

Kata kunci : human relation, disiplin, motivasi. 


\section{PENDAHULUAN}

Sumber daya modal dan kepemilikan aset berwujud lainnya bukanlah odal utama suatu organisasi atau perusahaan akan berhasil mencapai tujuan, karena yang terpenting adalah kualitas sumber daya manusia yang dimiliki. Kebutuhan akan sumber daya manusia yang sehat secara jasmani dan rohani, memiliki kesehatan mental yang baik serta memiliki kompetensi sesuai dengan kebutuhan organisasi adalah suatu syarat mutlak bagi setiap organisasi. Banyaknya keunggulan yang dimiliki organisasi, tidak akan dapat dimaksimalkan produktivitas tanpa adanya komunitas pegawai yang berkeahlian, kompeten, berdedikasi yang tinggi terhadap organisasi serta memiliki kinerja yang optimal (Samsuzdin (2016:121). Langkah awal yang dapat dilakukan perusahaan untuk mencapai tujuan adalah dengan menciptakan kepuasan kerja karyawannya.

Menurut Robbins dan Jugde (2016:110), menyatakan bahwa kepuasan kerja merupakan penilaian cerminan perasaan atau perilaku dari karyawan, maupun jumlah kepuasan yang dimiliki oleh karyawan terhadap pekerjaanya. Menurut Edy Sutrisno (2014:73), kepuasaan kerja menjadi masalah yang cukup menarik dan penting, karena terbukti besar manfaatnya bagi kepentingan individu, industri dan masyarakat. Untuk menciptakan kepuasan kerja, perusahaan bisa memulai dengan menciptakan hubungan kerja yang harmonis. Menurut Effendy (2016), menyatakan human relation merupakan syarat utama untuk keberhasilan suatu komunikasi yang baik antar perorangan ataupun komunikasi dalam instansi suatu perusahaan atau internal perusahaan. Menurut Robby Alam Fath (2015), menyatakan bahwa human relation berpengaruh positif dan signifikan terhadap kepuasan kerja karena hubungan yang kondusif dapat berpengaruh langsung terhadap karyawan dalam meningkatkan kepuasan kerja karyawan

Selain dari adanya hubungan yang harmonis, diperlukan juga adanya disiplin karyawan. Menurut Sedarmayanti (2016:82), menyatakan disiplin kerja merupakan tindakan manajemen untuk mendorong para anggota organisasi atau perusahaan untuk memenuhi tuntutan berbagai ketentuan yang harus diaati dan standar yang harus dipenuhi. Menurut Hasibuan (2016:193), menyatakan disiplin yang baik mencerminkan besarnya rasa tanggung jawab seseorang terhadap tugas-tugas yang diberikan kepadanya. Kepuasan kerja juga dapat dipengaruhi oleh adanya motivasi. Menurut Mahayasa (2018), disiplin kerja berpengaruh positif dan signifikan terhadap kepuasan kerja karena disiplin factor yang paling dominan maka perlu ditingkatkan agar harapan kepuasan kerja tercapai dan mendapatkan kepuasan dalam bekerja

Motivasi merupakan kondisi atau energi yang menggerakkan diri pegawai yang terarah atau tertuju untuk mencapai tujuan organisasi perusahaan (Anwar P.M (2015:291). Menurut Amirullah 
(2015:193), motivasi kerja dapat didefinisikan sebagai kondisi yang berpengaruh membangkitkan, mengarahkan dan memelihara perilaku yang berhubungan dengan lingkungan kerja. Menurut Nurun (2017), motivasi kerja dapat berpengaruh positif dan signifikan terhadap kepuasan kerja karyawan, artinya bahwa karyawan yang memiliki dan termotivasi positif, dapat meningkatkan efektivitas dan efisiensi mereka secara dratis untuk dapat mencapai tujuan organisasi.

PT. Orchid Boga Utama merupakan salah satu perusahaan yang bergerak di bidang perdagangan khususnya rumah makan (restaurant) yang memiliki 2 cabang/outlet yang berada di 2 (dua) daerah berbeda yaitu : UNO Restaurant yang beralamat di Jalan Raya Ubud, Gianyar Bali dan REDMANNA Restaurant yang beralamat di Jalan Cemara Sanur, Kota Denpasar. jumlah kunjungan dari konsumen pada tahun 2019 untuk masing-masing restaurant yang dimiliki oleh PT. Orchid Boga Utama. Dijelaskan bahwa cabang Red Manna restaurant mendapat kunjungan dari konsumen selama 1 tahun 2019 sejumlah 20,063 dan sedangkan UNO restaurant mendapakan kunjungan konsumen sebanyak 56,789 pada tahun yang sama. Dari jumlah tersebut, terdapat perbedaan jumlah kunjungan konsumen di masing-masing cabang. Perbedaan tersebut juga terlihat dari jumlah kunjungan konsumen UNO restaurant lebih banyak disetiap bulannya. Jumlah kunjungan yang dijabarkan pada bulan Juni, Juli, Agustus, September dan Oktober merupakan tingkat kunjungan dari konsumen yang tertinggi dari bulan-bulan lainnya yang biasa disebut dengan periode hight season, sedangkan tingkat kunjungan di bulan Januari, February, Maret, April, Mei, November dan Desember yang biasa disebut low season, mengalami penurunan tingkat kunjungan kunsumen ke cabang restaurant dari PT. Orchid Boga Utama.

Tujuan penelitian ini adalah (1) Untuk mengetahui pengaruh human relation terhadap kepuasan kerja karyawan pada PT. Orchid Boga Utama, (2) mengetahui pengaruh disiplin kerja terhadap kepuasan karyawan pada PT. Orchid Boga Utama, (3) mengetahui pengaruh motivasi terhadap kepuasan kerja karyawan pada PT. Orchid Boga Utama, dan (4) megetahui pengaruh human relation, disiplin dan motivasi terhadap kepuasan kerja karyawan pada PT. Orchid Boga Utama.

\section{TELAAH LITERATUR DAN HIPOTESIS}

\section{Human Relation}

Menurut Hasibuan (2012), menyatakan bahwa human relation yang baik antara seluruh pihak yang berkepentingan didalam perusahaan tentu akan mendorong pekerjaan yang menjadi tanggung jawab pribadi ataupun bersama akan selesai dengan baik, sehingga dapat mendorong meningkatnya kepuasan kerja yang dirasakan individu yang bekerja didalam sebuah organisasi. 
Menurut Ratih Dwi Antarai (2017), human relation merupakan hubungan yang dicirikan oleh keinginan untuk pendekatan satu sama lain karena memungkinkan kedua belah pihak untuk berinterkasi.

\section{Disiplin Kerja}

Menurut Sedarmayanti (2016:82), menyatakan disiplin merupakan tindakan manajemen untuk mendorong para anggota organisasi atau perusahaan untuk memenuhi tuntutan berbagai ketentuan yang harus ditaati dan standar yang harus dipenuhi. Menurut Veitzzal rivai (dalam Sinambela, 2016:476), disiplin kerja adalah suatu alat yang digunakan para manajer untuk berkomunikasi dengan karyawan agar mereka bersedia mengubah suatu perilaku serta sebagai upaya untuk meningkatkan kesadaran dan seseorang mentaati semua peraturan perusahaan dan norma-norma sosial yang berlaku.

\section{Motivasi}

Menurut Nurcahyani dan Dewi Adnyani (2016), menyatakan motivasi secara sederhana dapat dirumuskan sebagai kondisi atau tindakan yang mendorong seseorang untuk melakukan sebuah pekerjaan atau kegiatan semaksimal mungkin untuk berbuat dan berproduksi. Menurut Tirta Komara dan Euis Nelliwati (2014), menyatakan bahwa motivasi iti sendiri juga dapat dikatakan sebagai kekuatan yang mendorong sesorang untuk berprilaku kearah tujuan, juga merupakan factor penentu bagi keberhasilan organisasi.

\section{Kepuasan Kerja}

Menurut Priansa (2014:291), kepuasan kerja merupakan perasaan pegawai terhadap pekerjaannya, apakah senang suka atau tidak senang tidak suka sebagai hasil interaksi pegawai dengan lingkungan pekerjaannya atau sebagai presepsi sikap mental, juga sebagai hasil penilaian pegawai terhadap pekerjaannya. Menurut Sunyoto (2015:191), kepuasan kerja adalah "Keadaan emosional yang menyenangkan atau tidak menyenangkan di mana para karyawan memandang pekerjaannya. . Menurut Husein Umar (2012:36), berpendapat bahwa kepuasan kerja merupakan penilaian atau cerminan dari perasaan pekerjaaan terhadap pekerjaannya dimana hal tersebut tampak dalam sikap positif pekerjaannya.

\section{Hipotesis}

Adapun hipotesis yang diajukan dalam penelitian ini adalah sebagai berikut :

H1 : Di duga bahwa human relation berpengaruh positif dan signifikan terhadap kepuasan kerja karyawan pada PT. Orchid Boga Utama. 
H2 : Di duga bahwa disiplin kerja berpengaruh positif dan signifikan terhadap kepuasan kerja karyawan pada PT. Orchid Boga Utama.

H3 : Di duga bahwa motivasi kerja berpengaruh positif dan signifikan terhadap kepuasan kerja pada PT. Orchid Boga Utama.

H4 : Di duga bahwa human relation, displin, dan motivasi berpengaruh positif dan signifikan terhadap kepuasan kerja karyawan pada PT. Orchid Boga Utama.

\section{METODE PENELITIAN}

\section{Desain Penelitian}

Peranan human relation, disiplin dan motivasi kerja sangat di perlukan dalam perusahaan agar dapat berjalan dengan baik. Untuk dapat mengetahui adanya pengaruh antara human relation, disiplin dan motivasi terhadap kepuasan kerja, maka akan diuraian kembali dalam bentuk gambar sebagaimana nampak pada Gambar 1.

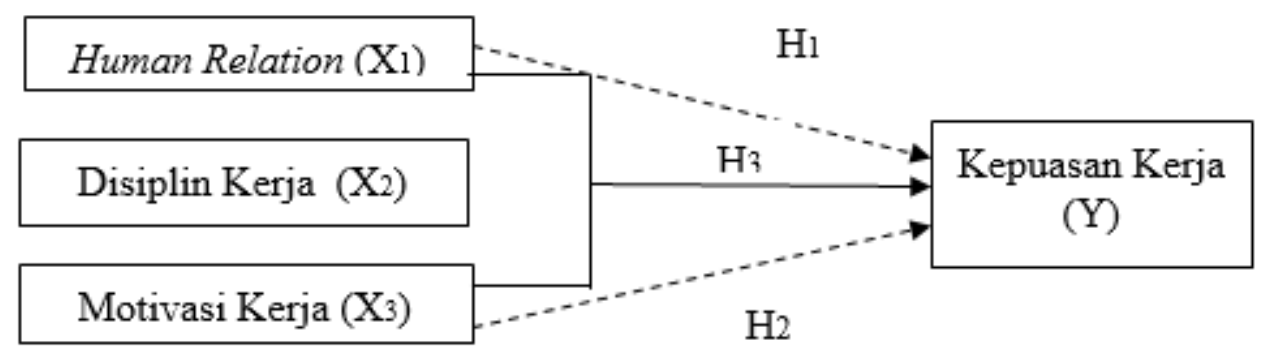

\section{Gambar 1 Kerangka Konseptual}

\section{Populasi dan Sampel}

Populasi yang menjadi subyek penelitian ini adalah seluruh karyawan pada PT. Orchid Boga Utama yang berjumlah 75 orang, dan selutuh anggota populasi dilibatkan sebagai subyek penelitian, sehingga penelitian ini menggunakan mtode sensus.

\section{Metode Pengumpulan Data}

Untuk mendapatkan data yang sesuai dengan kebutuhan penelitian maka digunakan beberapa metode pengumpulan data, di antaranya observasi, wawancara, kuisioner, studi pustaka, dan dokumentasi. Kuisioner dalam penelitian ini ditujukan kepada subyek penelitian yaitu karyawan PT Orchid Boga Utama dan untuk mendapatkan jawaban terkait variabel penelitian maka 
digunakan Skala Likert dengan lima pilihan jawaban yaitu sanat tidak setuju diberi nilai 1, tidak setuju diberi nilai 2, netral diberi nilai 3, setuju diberi nilai 4, dan sangat setuju diberi nilai 5 .

\section{Analisis Data}

1. Uji instrumen penelitian. Uji validitas, yang berarti instrument tersebut dapat digunakan untuk mengukur apa yang seharusnya diukur, dan uji reliabilitas instrument untuk menguji konsistensi instrumen yang bila digunakan beberapa kali untuk mengukur obyek yang sama, akan menghasilkan data yang sama.

2. Uji asumsi klasik, terdiri atas atas uji normalitas, uji multikolinearitas, uji heterokedastisitas.

3. Analisis regresi linear berganda. Analisis ini dipergunakan untuk mengetahui besarnya nilai estimasi (pengaruh) variabel-variabel bebas terhadap variabel terikat secara parsial dan serempak.

\section{HASIL DAN PEMBAHASAN}

\section{Uji Instrumen Penelitian.}

Berdasarkan Tabel 1, diketahui bahwa seluruh pernyataan memiliki koefisien korelasi yang lebih besar dari 0,30. Jadi dapat disimpulkan bahwa seluruh indikator telah memenuhi syarat validitas data.

Untuk mengukur reliabilitas dengan uji statistik cronbach alpha lebih besar dari 0,60. Hasil uji menunjukkan nilai cronbach alpha pada Tabel 2. Berdasarkan Tabel 2, dapat dilihat bahwa semua variabel telah memenuhi syarat reliabilitas data.

\section{Karakteristik Responden}

Dari Tabel 3 dapat dilihat bahwa responden dalam penelitian ini terbagi menjadi 2 yaitu laki-laki sebanyak 34 orang (45,33\%) dan responden perempuan sebanyak 41 orang $(54,67 \%)$. Hal ini berarti sebagian besar responden pada PT. Orchid Boga Utama cenderung berjenis kelamin perempuan. 
Tabel 1.Hasil Uji Validitas Variabel

\begin{tabular}{|c|c|c|c|}
\hline \multicolumn{4}{|c|}{ Variabel Human Relation } \\
\hline No & Indikator & Koefisien Korelasi & Keterangan \\
\hline 1 & $\mathrm{X}_{1.1}$ & 0,637 & Valid \\
\hline 2 & $\mathrm{X}_{1.2}$ & 0,742 & Valid \\
\hline 3 & $\mathrm{X}_{1.3}$ & 0,694 & Valid \\
\hline 4 & $X_{1.4}$ & 0,804 & Valid \\
\hline \multicolumn{4}{|c|}{ Variabel Disiplin } \\
\hline No & Indikator & Koefisien Korelasi & Keterangan \\
\hline 1 & $\mathrm{X}_{2.1}$ & 0,710 & Valid \\
\hline 2 & $\mathrm{X}_{2} .2$ & 0,581 & Valid \\
\hline 3 & $\mathrm{X}_{2.3}$ & 0,588 & Valid \\
\hline 4 & $\mathrm{X}_{2.4}$ & 0,695 & Valid \\
\hline 5 & $X_{2} .5$ & 0,782 & Valid \\
\hline \multicolumn{4}{|c|}{ Variabel Motivasi Kerja } \\
\hline No & Indikator & Koefisien Korelasi & Keterangan \\
\hline 1 & $\mathrm{X}_{3.1}$ & 0,685 & Valid \\
\hline 2 & $\mathrm{X}_{3} .2$ & 0,738 & Valid \\
\hline 3 & $\mathrm{X}_{3.3}$ & 0,672 & Valid \\
\hline 4 & $X_{3.4}$ & 0,779 & Valid \\
\hline 5 & $X_{3} .5$ & 0,610 & Valid \\
\hline \multicolumn{4}{|c|}{ Variabel Kepuasan Kerja Karyawan } \\
\hline No & Indikator & Koefisien Korelasi & Keterangan \\
\hline 1 & Y.1 & 0,789 & Valid \\
\hline 2 & Y.2 & 0,508 & Valid \\
\hline 3 & Y.3 & 0,771 & Valid \\
\hline 4 & Y.4 & 0,722 & Valid \\
\hline 5 & Y.5 & 0,688 & Valid \\
\hline
\end{tabular}

Sumber: Data Diolah, 2020

Tabel 2. Hasil Uji Reliabilitas

\begin{tabular}{llll}
\hline No & Variabel & Cronbach Alpha & Keterangan \\
\hline $\mathbf{1}$ & Human Relation & 0,690 & Reliabel \\
$\mathbf{2}$ & Disiplin & 0,688 & Reliabel \\
$\mathbf{3}$ & Motivasi Kerja & 0,732 & Reliabel \\
$\mathbf{4}$ & Kepuasan Kerja Karyawan & $\mathbf{0 , 7 3 2}$ & Reliabel \\
\hline
\end{tabular}

Sumber: Data Diolah, (2020) 
Tabel 3. Karakteristik Responden Berdasarkan Jenis Kelamin

\begin{tabular}{lll}
\hline Jenis Kelamin & $\begin{array}{l}\text { Jumlah Responden } \\
\text { (Orang) }\end{array}$ & $\begin{array}{l}\text { Persentase } \\
(\mathbf{\%})\end{array}$ \\
\hline Laki-Laki & 34 & 45,33 \\
Perempuan & 41 & 54,67 \\
Jumlah & $\mathbf{7 5}$ & $\mathbf{1 0 0}$ \\
& & \\
\hline
\end{tabular}

Sumber : data diolah (2020)

Pada Tabel 4, dapat dinyatakan bahwa responden yang terbanyak berusia 22-30 Tahun sebanyak 29 orang $(38,67 \%)$, dan jumlah terkecil adalah diatas 50 Tahun sebanyak 7 orang (9,33\%). Hal ini mengindikasikan bahwa karyawan pada PT. Orchid Boga Utama cenderung lebih banyak berusia produktif.

Tabel 4. Karakteristik Responden Berdasarkan Usia

\begin{tabular}{lll}
\hline Usia & $\begin{array}{l}\text { Jumlah Responden } \\
\text { (Orang) }\end{array}$ & $\begin{array}{l}\text { Persentase } \\
(\%)\end{array}$ \\
& 18 & 24,00 \\
\hline 221 Tahun & 29 & 38,67 \\
31-40 Tahun & 11 & 16,00 \\
41-50 Tahun & 9 & 12,00 \\
>50 tahun & 7 & 9,33 \\
Jumlah & $\mathbf{7 5}$ & $\mathbf{1 0 0}$ \\
\hline
\end{tabular}

Sumber : data diolah (2020)

Pada Tabel 5, dapat dinyatakan bahwa responden yang terbanyak berpendidikan Sarjana sebanyak 34 orang (37,37\%), dan jumlah terkecil adalah berpendidikan SMP/SLTP sebanyak 1 orang (1,33\%). Hal ini mengindikasikan bahwa karyawan Pada PT. Orchid Boga Utama lebih dominan berpendidikan Sarjana, dimana seluruh responden sudah memiliki tingkat pendidikan yang cukup tinggi. 
Tabel 5. Karakteristik Responden Menurut Tingkat Pendidikan

\begin{tabular}{lll}
\hline Tingkat Pendidikan & $\begin{array}{l}\text { Jumlah } \\
\text { (Orang) }\end{array}$ & $\begin{array}{l}\text { Persentase } \\
(\mathbf{\%})\end{array}$ \\
\hline SMP/SLTP & 1 & 1,33 \\
SMA/SLTA & 14 & 18,67 \\
D1/D2/D3 & 26 & 34,67 \\
Sarjana & 34 & 45,33 \\
Total & $\mathbf{7 5}$ & $\mathbf{1 0 0}$ \\
\hline
\end{tabular}

Sumber : data diolah (2020)

Pada Tabel 6, dapat dinyatakan bahwa responden berpenghasilan dibawah Rp. 1.500.000 sebanyak 0 orang (0,00\%), Rp. 1.500 .000 - Rp. 3.000 .000 sebanyak 29 orang (38,67\%) dan diatas Rp. 3.000.000 sebanyak 46 orang (61,33\%), . Hal ini Mengindikasikan bahwa responden Pada PT. Orchid Boga Utama telah memiliki penghasilan yang cukup baik untuk menunang kegiatan seharihari.

\section{Tabel 6}

Karakteristik Responden Menurut Penghasilan

\begin{tabular}{lll}
\hline Penghasilan & Jumlah & Persentase \\
\cline { 2 - 3 } & (Orang) & $\mathbf{( \% )}$ \\
< Rp. 1.500.000 & 0 & 0,00 \\
Rp. 1.500.000-Rp. 3.000.000 & 29 & 38,67 \\
$>$ Rp. 3.000.000 & 46 & 61,33 \\
Total & $\mathbf{7 5}$ & $\mathbf{1 0 0}$ \\
\hline
\end{tabular}

Sumber : data diolah (2020)

\section{Deskripsi Jawaban Responden}

Berdasarkan Tabel 7, dapat dilihat bahwa seluruh penilaian katagori seluruh pernyataan kuesioner termasuk dalam katagori baik dengan rata-rata skor sebesar 3,89. Jawaban dengan nilai rata-rata tertinggi terdapat dalam pernyataan no 2 dengan nilai rata-rata sebesar 4,24 yang menyatakan bahwa karyawan PT. Orchid Boga Utama mendengarkan intruksi/perintah dari atasan. Sedangkan untuk nilai rata-rata jawaban terendah terdapat dalam pernyataan no 1 dengan nilai ratarata sebesar 3,60 dimana menyatakan bahwa hubungan antar karyawan PT. Orchid Boga Utama harmonis. 
Tabel 7.Kriteria dan Jawaban Penilaian Jawaban Kuesioner Variabel Human Relation

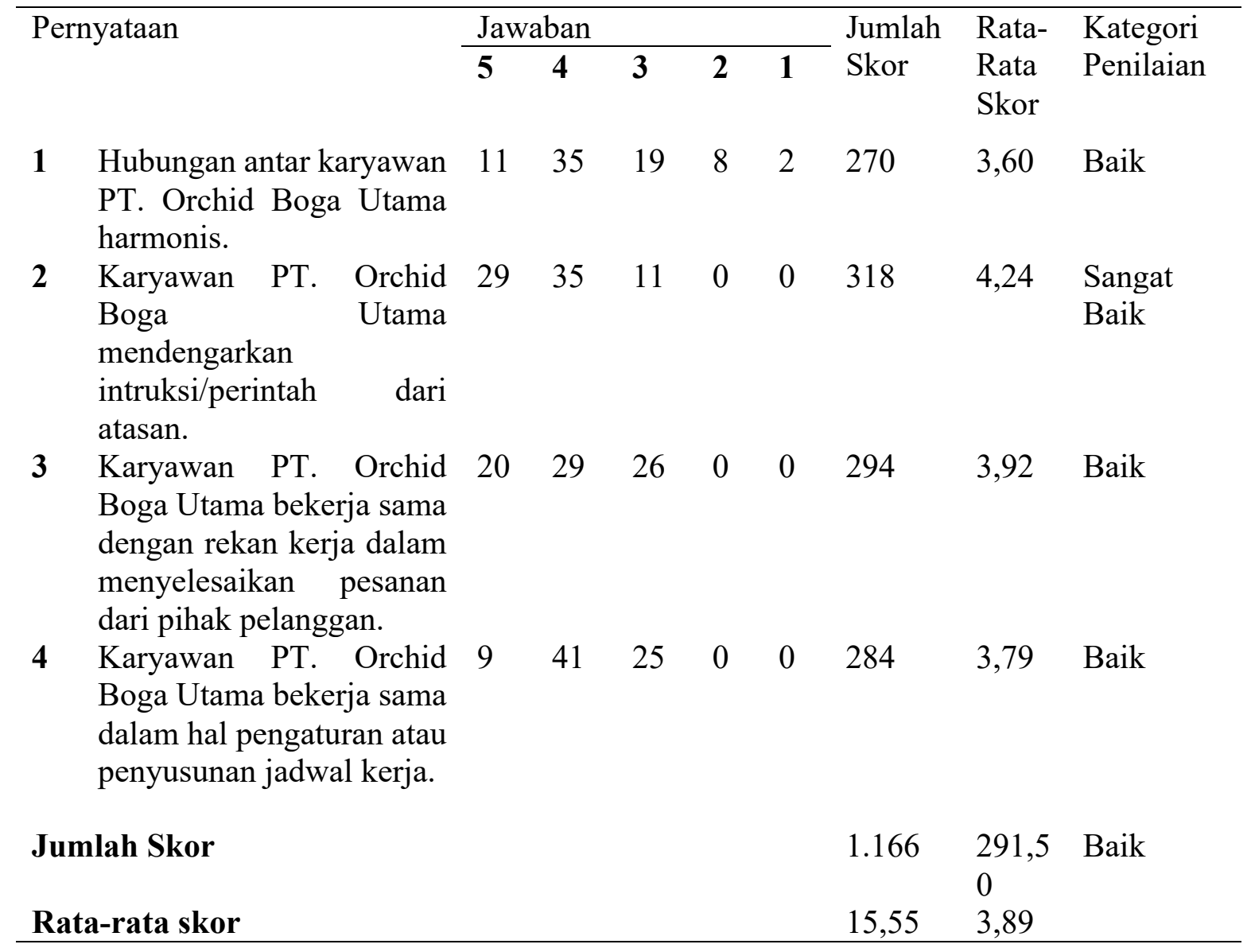

Sumber : data diolah, 2020

Berdasarkan Tabel 8 dapat dilihat bahwa seluruh penilaian katagori seluruh pernyataan kuesioner termasuk dalam katagori baik dengan skor rata-rata sebesar 3,75. Jawaban dengan nilai rata-rata tertinggi terdapat dalam pernyataan no 1 dengan nilai rata-rata sebesar 3,92 menyatakan bahwa karyawan merasa bahwa kedisiplinan karyawan PT. Orchid Boga Utama akan tercipta apabila hubungan kemanusiaan dalam instansi berjalan dengan baik. Sedangkan untuk nilai ratarata jawaban terendah terdapat dalam pernyataan no 3 dengan nilai rata-rata sebesar 3,63 dimana menyatakan bahwa kehadiran karyawan PT. Orchid Boga Utama sangat mempengaruhi kedisiplinan. 
Tabel 8. Kriteria dan Jawaban Penilaian Jawaban Kuesioner Variabel Disiplin

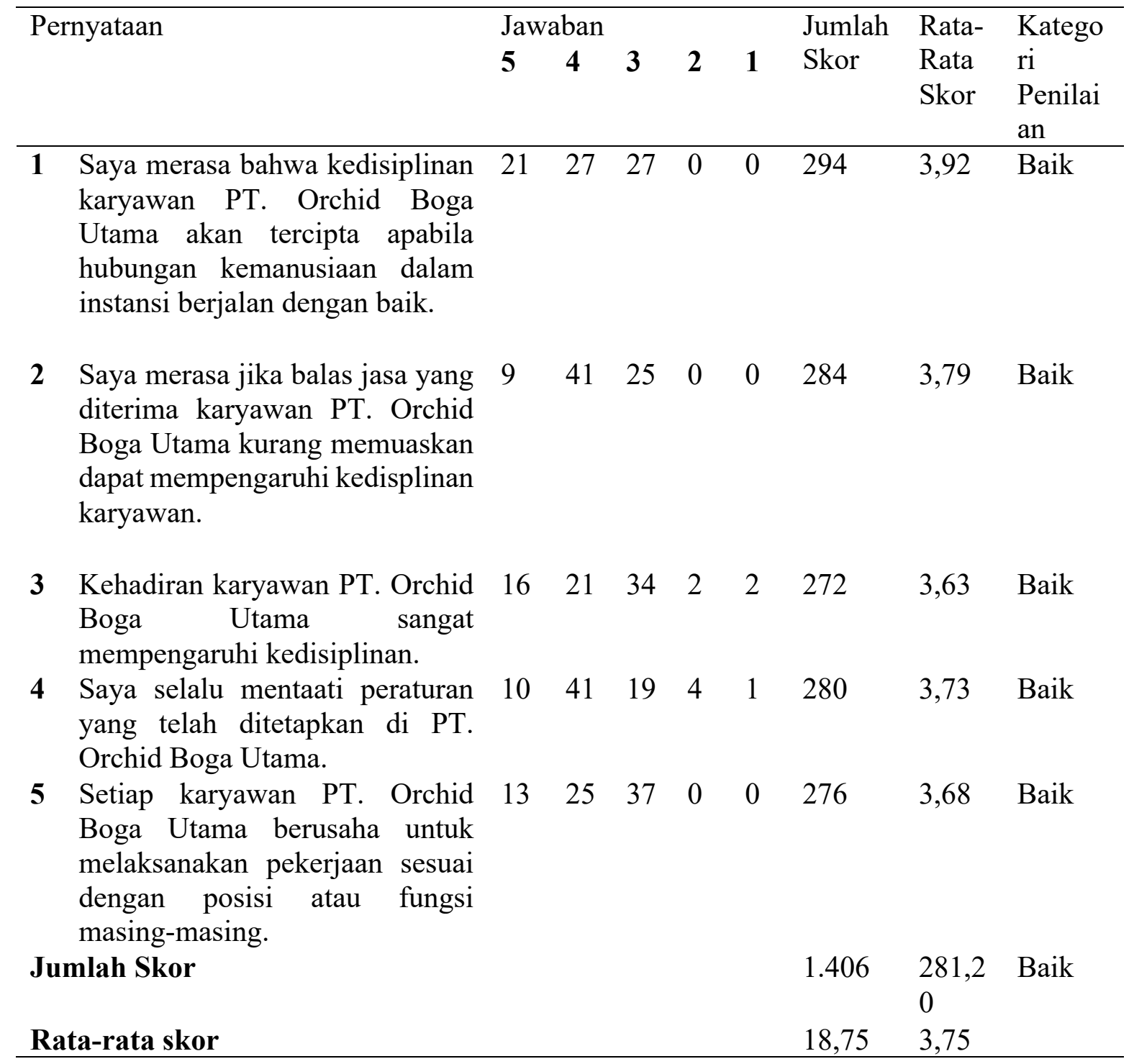

Sumber : data diolah, 2020

Berdasarkan Tabel 9 dapat dilihat bahwa seluruh penilaian katagori seluruh pernyataan kuesioner termasuk dalam katagori baik dengan skor rata-rata sebesar 3,91. Jawaban dengan nilai rata-rata tertinggi terdapat dalam pernyataan no 2 dengan nilai rata-rata sebesar 4,48 menyatakan bahwa karyawan yang bekerja di PT. Orchid Boga Utama mendapatkan jaminan asuransi keselamatan. Sedangkan untuk nilai rata-rata jawaban terendah terdapat dalam pernyataan no 5 dengan skor rata-rata sebesar 3,73 dimana menyatakan bahwa pimpinan PT. Orchid Boga Utama memberikan kesempatan kepada karyawan untuk mengembangkan ketrampilan dan kemampuan dalam bekerja. 
Tabel 9. Kriteria dan Jawaban Penilaian Jawaban Kuesioner Variabel Motivasi Kerja

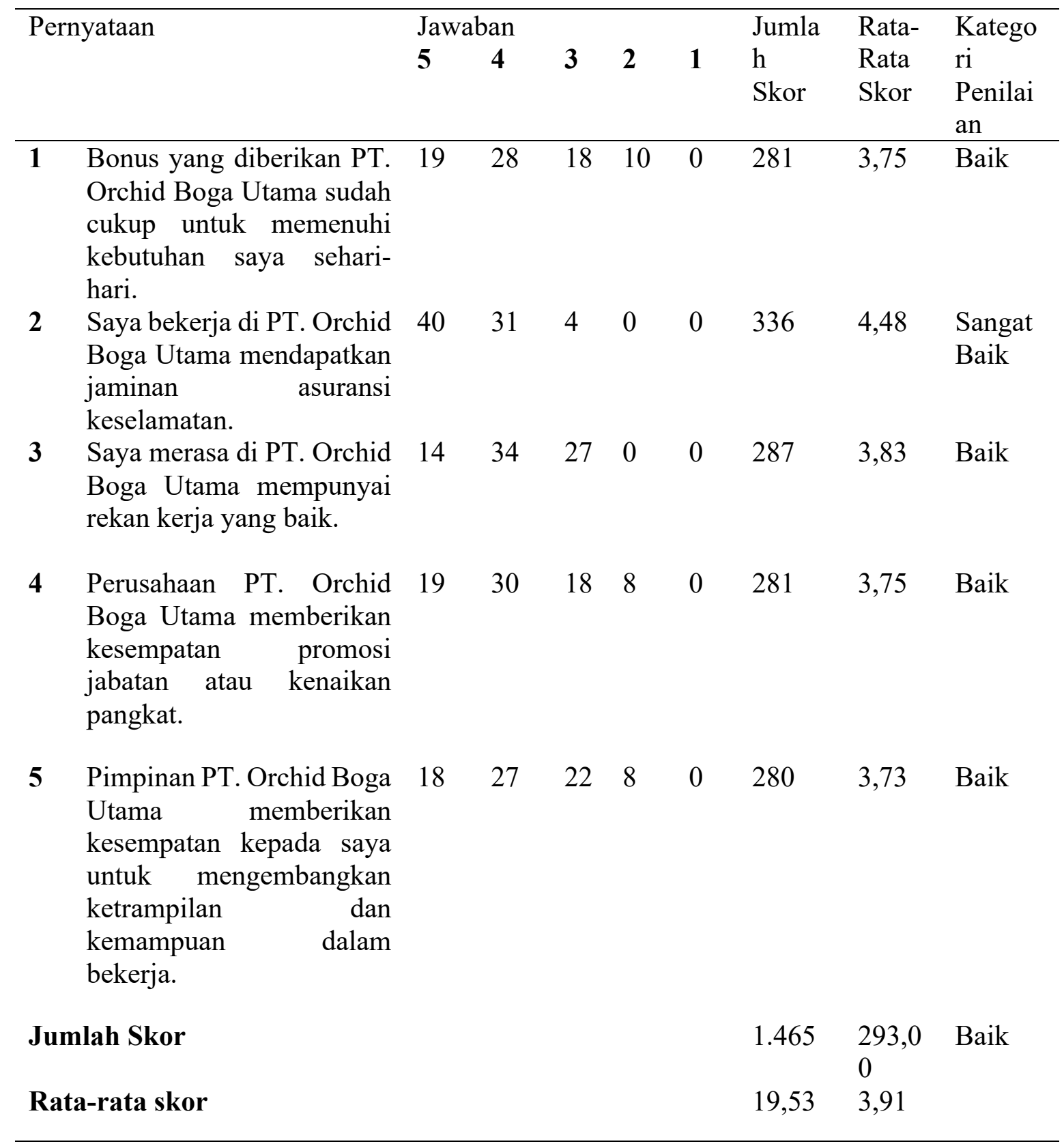

Sumber : data diolah, 2020

Berdasarkan Tabel 10 dapat dilihat bahwa seluruh penilaian katagori seluruh pernyataan kuesioner termasuk dalam katagori baik dengan skor rata-rata sebesar 3,86. Jawaban dengan nilai rata-rata tertinggi terdapat dalam pernyataan no 5 dengan nilai rata-rata sebesar 4,12 menyatakan bahwa lingkungan kerja PT. Orchid Boga Utama sangat mempengaruhi karyawan dalam bekerja baik secara langsng maupun tidak langsung. Sedangkan untuk nilai rata-rata jawaban terendah terdapat dalam pernyataan no 3 dengan skor rata-rata sebesar 3,67 dimana menyatakan bahwa 
karyawan merasa pimpinan PT. Orchid Boga Utama memberikan pengawasan/pengarahan kepada tingkat karyawan yang ada dibawahnya.

Tabel 10. Kriteria dan Jawaban Penilaian Jawaban Kuesioner Variabel Kepuasan Kerja Karyawan

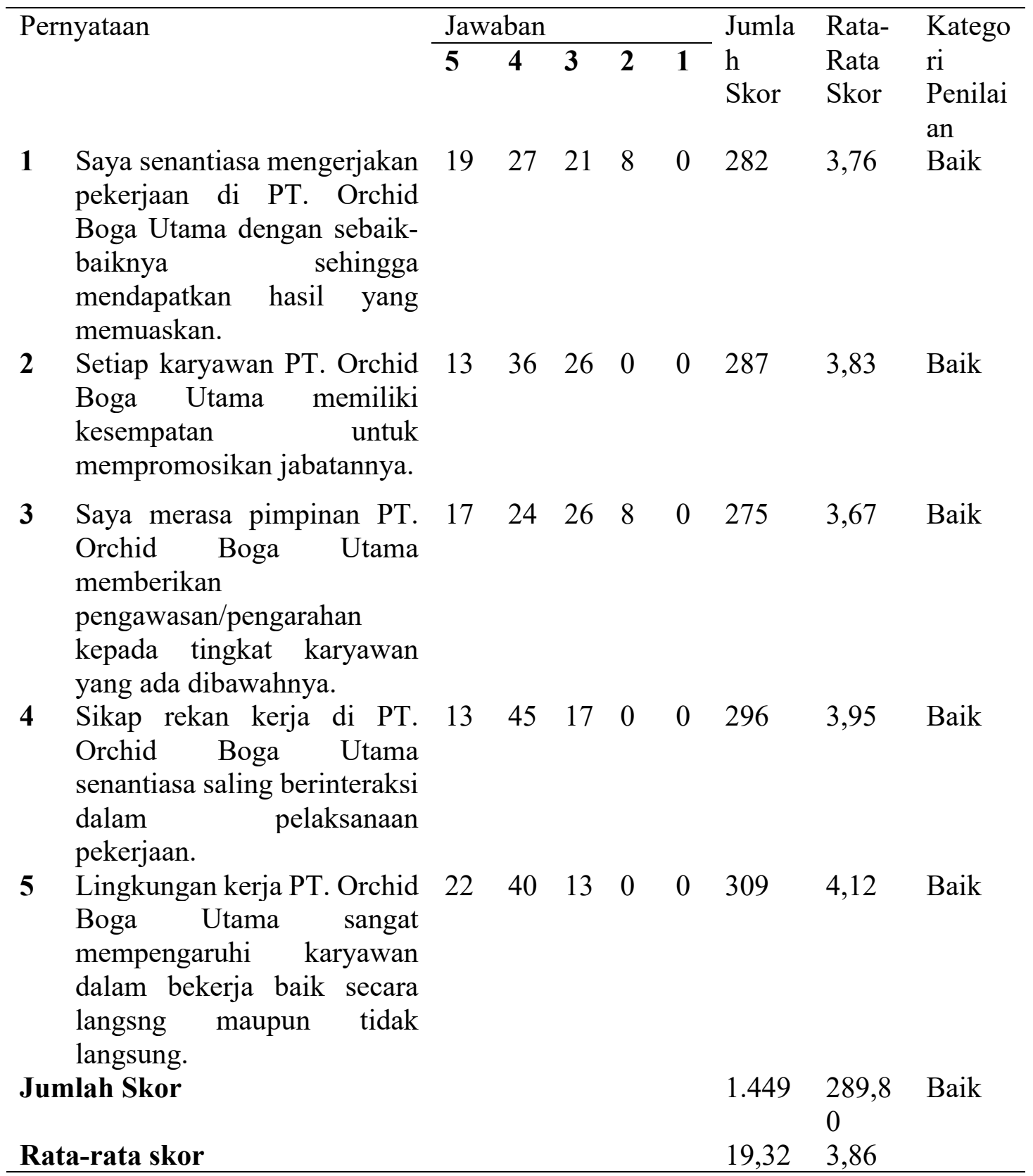

Sumber : data diolah, 2020

\section{Uji Asumsi Klasik}

1. Uji Normalitas

Berdasarkan Tabel 11, terlihat bahwa nilai Sig.(2-tailed) sebesar 0,144 >0,05. Oleh sebab itu Ho tidak dapat ditolak. Hal itu berarti nilai residual terstandarisasi dinyatakan menyebar secara normal. 
Tabel 11 . Uji Normalitas

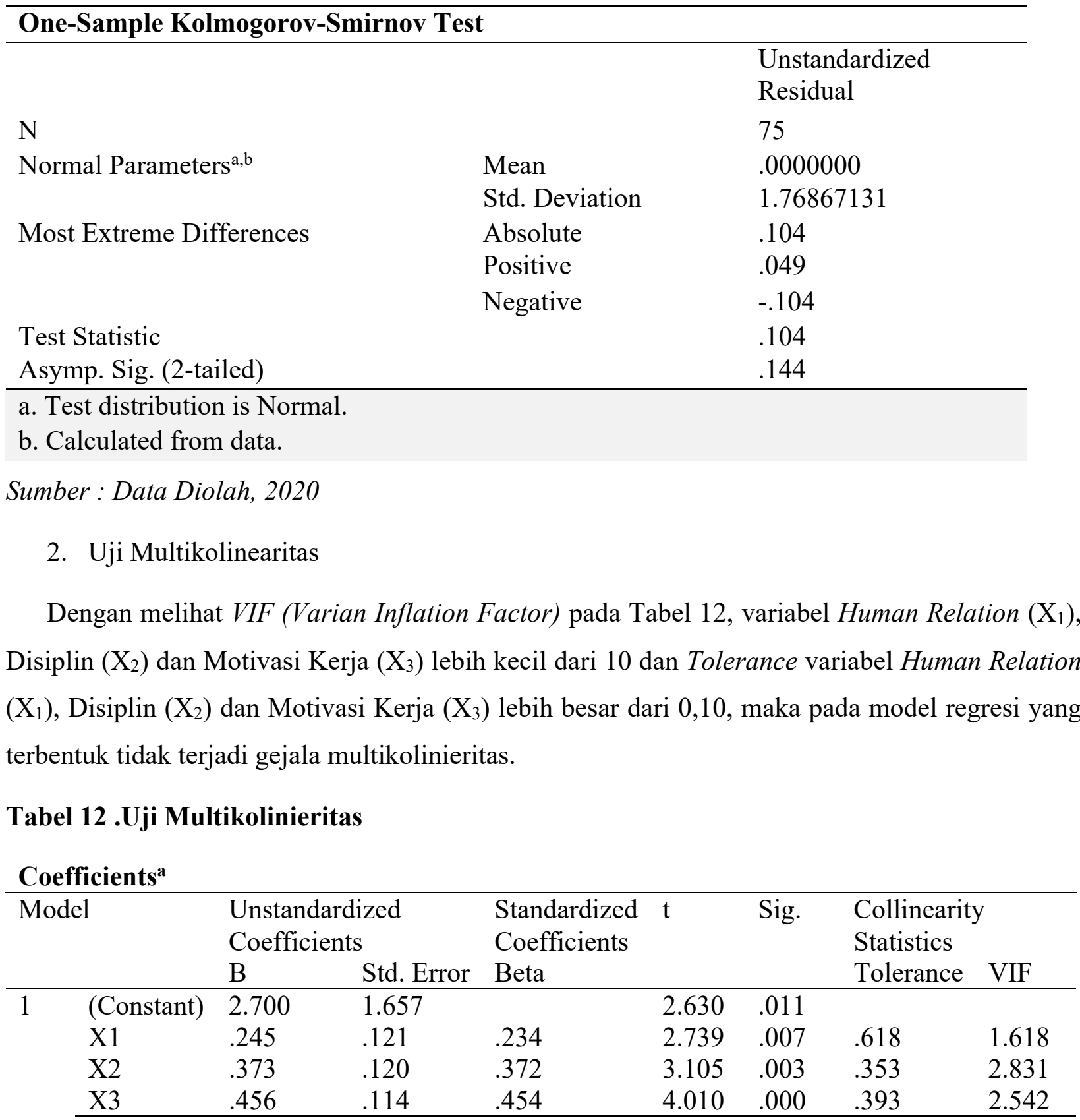

a. Dependent Variable: Y

Sumber : Data Diolah, 2020

3. Uji Heteroskedastisitas

Berdasarkan Tabel 13 diketahui bahwa pada model regresi tidak terjadi gejala heteroskesdastisitas. Hasil ini karena Sig. variabel Human Relation $\left(\mathrm{X}_{1}\right)$ terdapat absolut residual sebesar 0,272 >0,05, variabel Disiplin $\left(\mathrm{X}_{2}\right)$ terdapat absolut residual sebesar 0,324 $>0,05$ dan variabel Motivasi Kerja 
$\left(\mathrm{X}_{3}\right)$ terdapat absolut residual sebesar 0,129>0,05 maka pada model regresi yang terbentuk tidak terjadi gejala heteroskesdastisitas.

Tabel 13.Hasil Uji Heteroskesdastisitas.

\begin{tabular}{|c|c|c|c|c|c|c|}
\hline \multicolumn{7}{|c|}{ Coefficients $^{\mathrm{a}}$} \\
\hline \multicolumn{2}{|c|}{ Model } & \multicolumn{2}{|c|}{ Unstandardized Coefficients } & Standardized & $\mathrm{t}$ & Sig. \\
\hline \multirow{4}{*}{1} & (Constant) & 4.358 & 875 & & 1981 & 052 \\
\hline & $\mathrm{X} 1$ & -.071 & .064 & -.153 & -1.107 & .272 \\
\hline & $\mathrm{X} 2$ & .063 & .063 & .181 & .992 & .324 \\
\hline & X3 & -.153 & .060 & -.440 & -2.550 & .129 \\
\hline
\end{tabular}

a. Dependent Variable: Abs_Ut

Sumber : Data Diolah, 2020

\section{Analisis Regresi Linear Berganda}

Pengujian hipotesis dilakukan untuk menguji hipotesis yang diajukan. Hipotesis yang diajukan dalam penelitian ini terkait variabel Human Relation dan Disiplin. Analisis regresi berganda dipilih untuk menganalisis pengujian hipotesis dalam penelitian ini. Hasil analisis dapat dilihat pada Tabel 14 .

Berdasarkan tabel diatas dapat diketahui persamaan regresinya menjadi $Y=\alpha+\beta_{1} . X_{1}+\beta_{2} . X_{2}+\beta_{3} . X_{3}+\varepsilon i$

Dari persamaan diatas maka dapat dibuat persamaan regresi penelitian ini adalah : $\mathrm{Y}=2,700+$ $0,245 \mathrm{X}_{1}+0,373 \mathrm{X}_{2}+0,456 \mathrm{X}_{3}+\varepsilon \mathrm{i}$

\section{Tabel 14.Hasil Uji Regresi Linear Berganda}

\begin{tabular}{|c|c|c|c|c|c|c|}
\hline \multicolumn{7}{|c|}{ Coefficients $^{\mathrm{a}}$} \\
\hline & & \multicolumn{2}{|c|}{ Unstandardized Coefficients } & \multirow{2}{*}{$\begin{array}{l}\text { Standardized } \\
\text { Coefficients } \\
\text { Beta }\end{array}$} & \multirow[t]{2}{*}{$\mathrm{t}$} & \multirow[t]{2}{*}{ Sig. } \\
\hline & & B & Std. Error & & & \\
\hline \multirow[t]{4}{*}{1} & (Constant) & 2.700 & 1.657 & & 2.630 & .011 \\
\hline & $\mathrm{X} 1$ & .245 & .121 & .234 & 2.739 & .007 \\
\hline & $\mathrm{X} 2$ & .373 & .120 & .372 & 3.105 & .003 \\
\hline & $\mathrm{X} 3$ & .456 & .114 & .454 & 4.010 & .000 \\
\hline
\end{tabular}

a. Dependent Variable: Y

Sumber : Data Diolah, 2020

Interprestasi dari koefisien regresi : 
$\alpha=2,700 \quad$ secara statistik menunjukan bahwa Kepuasan Kerja Karyawan akan meningkat sebesar 2,700 persen dengan syarat variabel lain dalam penelitian ini yakni Human Relation $\left(\mathrm{X}_{1}\right)$, Disiplin $\left(\mathrm{X}_{2}\right)$ dan Motivasi Kerja $\left(\mathrm{X}_{3}\right)$ diasumsikan sama dengan nol.

$\beta 1=0,245$ secara statistik menunjukkan ada pengaruh positif antara variabel Human Relation $\left(\mathrm{X}_{1}\right)$ terhadap Kepuasan Kerja Karyawan (Y) sebesar 0,245 yang artinya setiap terjadi (adanya) peningkatan Human Relation sebesar satu satuan maka akan menyebabkan meningkatnya Kepuasan Kerja Karyawan sebesar 0,245 dengan syarat variabel lain diasumsikan sama dengan nol.

$\beta 2=0,373$ secara statistik menunjukkan ada pengaruh positif antara variabel Disiplin $\left(\mathrm{X}_{2}\right)$ terhadap Kepuasan Kerja Karyawan (Y) sebesar 0,373 yang artinya setiap terjadi kenaikan (adanya) Disiplin sebesar satu satuan maka akan menyebabkan meningkatanya Kepuasan Kerja Karyawan sebesar 0,373 dengan syarat variabel lain diasumsikan sama dengan nol.

$\beta 3=0,456 \quad$ secara statistik menunjukkan ada pengaruh positif antara variabel Motivasi Kerja $\left(\mathrm{X}_{3}\right)$ terhadap Kepuasan Kerja Karyawan (Y) sebesar 0,456 yang artinya setiap terjadi kenaikan (adanya) Motivasi Kerja sebesar satu satuan maka akan menyebabkan meningkatanya Kepuasan Kerja Karyawan sebesar 0,456 dengan syarat variabel lain diasumsikan sama dengan nol.

\section{Analisis Koefisien Determinasi}

Berdasarkan Tabel 15, koefisien determinasi yang ditunjukkan dari nilai Adjusted R Square sebesar 0,724. Hal ini berarti variabel dependen Kepuasan Kerja Karyawan (Y) dapat dijelaskan oleh tiga variabel independen yaitu Human Relation $\left(\mathrm{X}_{1}\right)$, Disiplin $\left(\mathrm{X}_{2}\right)$ dan Motivasi Kerja $\left(\mathrm{X}_{3}\right)$ sebesar $72,40 \%$ sedangkan sisanya 0,276 atau $27,60 \%$ dijelaskan oleh variabel atau sebab - sebab lainnya di luar model penelitian.

\section{Tabel 15. Hasil Uji Analisis Koefisien Determinasi $\left(\mathbf{R}^{2}\right)$}

\begin{tabular}{|c|c|c|c|c|}
\hline \multicolumn{5}{|c|}{ Model Summary } \\
\hline Model & $\mathrm{R}$ & R Square & Adjusted R Square & $\begin{array}{l}\text { Std. Error of the } \\
\text { Estimate }\end{array}$ \\
\hline 1 & $.900^{\mathrm{a}}$ & .740 & .724 & 1.806 \\
\hline
\end{tabular}

a. Predictors: (Constant), X3, X1, X2

Sumber : Data Diolah, 2020

Uji Signifikansi Parsial (t-test) 
1. Pengaruh human relation terhadap kepuasan kerja. Dari hasil penelitian diketahui adanya pengaruh positif dan signifikan Human Relation terhadap Kepuasan Kerja Karyawan. Hal ini dibuktikan dengan nilai $\beta 1=0,245$ serta $t_{\text {hitung }}(2,739)>t_{\text {tabel }}(1,658)$ dan sig. $0,007<$ 0,05 maka $\mathrm{H} 1$ diterima. Ini berarti bahwa secara statistik Human Relation $\left(\mathrm{X}_{1}\right)$ berpengaruh signifikan terhadap Kepuasan Kerja Karyawan (Y). Penelitian Anzhari (2018), menemukan human relation mempunyai pengaruh terhadap kepuasan kerja karyawan.2.

2. Pengaruh disiplin kerja terhadap kepuasan kerja. Dari hasil penelitian diketahui adanya pengaruh positif dan signifikan Disiplin terhadap Kepuasan Kerja Karyawan. Hal ini dibuktikan dengan nilai $\beta 2=0,373$ serta $t_{\text {hitung }}(3,105)>t_{\text {tabel }}(1,658)$ dan sig. $0,003<0,05$ maka $\mathrm{H} 2$ diterima, yang berarti bahwa secara statistik disiplin $\left(\mathrm{X}_{2}\right)$ berpengaruh signifikan terhadap Kepuasan Kerja Karyawan (Y). Dengan demikian hipotesis yang menyatakan bahwa Disiplin $\left(\mathrm{X}_{2}\right)$ berpengaruh positif dan signifikan secara parsial terhadap Kepuasan Kerja Karyawan (Y) Pada PT. Orchid Boga Utama teruji kebenarannya. Penelitian Ariani dan Assarofa (2018), menemukan bukti bahwa disiplin berpengaruh positif terhadap kepuasan kerja karyawan.

3. Pengaruh motivasi kerja terhadap kepuasan kerja. Dari hasil penelitian diketahui adanya pengaruh positif dan signifikan Motivasi Kerja terhadap Kepuasan Kerja Karyawan. Hal ini dibuktikan dengan nilai $\beta 3=0,456$ serta $t_{\text {hitung }}(4,010)>t_{\text {tabel }}(1,658)$ dan sig. $0,000<$ 0,05 maka H3 diterima. Ini berarti bahwa secara statistik motivasi kerja $\left(\mathrm{X}_{3}\right)$ berpengaruh signifikan terhadap kepuasan kerja karyawan (Y). Dengan demikian hipotesis yang menyatakan bahwa Motivasi Kerja $\left(\mathrm{X}_{3}\right)$ berpengaruh positif dan signifikan terhadap Kepuasan Kerja Karyawan (Y) teruji kebenarannya.

\section{Uji Sigifikansi Simultan (F-Test)}

Uji f-test digunakan untuk menguji $\mathrm{H} 4$, yaitu pengaruh Human Relation $\left(\mathrm{X}_{1}\right)$ Disiplin $\left(\mathrm{X}_{2}\right)$ dan Motivasi Kerja $\left(\mathrm{X}_{3}\right)$ secara simultan berpengaruh terhadap Kepuasan Kerja Karyawan (Y).

\section{Tabel 16. Hasil Uji Signifikan Simultan (Uji F-Test)}

\begin{tabular}{lllllll}
\hline $\begin{array}{l}\text { ANOVA } \\
\text { Model }\end{array}$ & Sum of Squares & df & Mean Square & F & Sig. \\
\hline 1 & Regression & 410.833 & 3 & 136.944 & 42.003 & .000 \\
& Residual & 231.487 & 71 & 3.260 & & \\
& Total & 642.320 & 74 & & & \\
\hline
\end{tabular}

a. Dependent Variable: Y 
Sumber : Data Diolah, 2020

Tabel 16 menunjukkan bahwa variabel independen yang terdiri Human Relation, Disiplin dan Motivasi Kerja berpengaruh terhadap Kepuasan Kerja Karyawan. Hal ini dibuktikan dengan nilai $F_{\text {tabel }}(2,68)<F_{\text {hitung }}(42,003)$ dan sig. 0,000 $<0,05$ maka H4 diterima. Ini berarti bahwa dan Motivasi Kerja berpengaruh positif dan signifikan terhadap Kepuasan Kerja Karyawan. Dengan demikian hipotesis yang menyatakan bahwa dan Motivasi Kerja berpengaruh positif dan signifikan terhadap Kepuasan Kerja Karyawan teruji kebenarannya.

\section{Simpulan}

Berdasarkan data yang diperoleh dari hasil analisis dapat ditarik kesimpulan sebagai berikut :

1. Human relation berpengaruh positif dan signifikan terhadap kepuasan kerja karyawan pada PT. Orchid Boga Utama.

2. Disiplin berpengaruh positif dan signifikan terhadap kepuasan kerja karyawan pada PT. Orchid Boga Utama.

3. Motivasi kerja berpengaruh positif dan signifikan terhadap kepuasan kerja karyawan pada PT. Orchid Boga Utama.

4. Human relation, disiplin dan motivasi kerja berpengaruh positif dan signifikan terhadap kepuasan kerja karyawan pada PT. Orchid Boga Utama.

\section{Saran}

1. Berdasarkan hasil penelitian, nilai rata-rata jawaban terendah pada vaiabel Human Relation terdapat dalam pernyataan no 1 dengan nilai rata-rata sebesar 3,60 dimana menyatakan bahwa hubungan antar karyawan PT. Orchid Boga Utama harmonis. Maka diharapkan kepada manajemen perusahaan dan seluruh anggota organisasi mampu menjalin hubungan kerja yang harmonis sehingga timbur rasa aman dan nyaman dalam bekerja dan pada akhirnya dapat mencapai target yang ditentukan perusahaan.

2. Diharapkan manajemen PT. Orchid Boga Utama meningatkan disiplin kerja karyawan bukan hanya deri absensi semata melainkan dari menjalin rasa kerjasama, rasa kekeluargaan ataupun melibatkan karyawan dalam pengambilan keputusan untuk membangun perusahaan karena berdasarkan hasil nilai rata-rata jawaban terendah pada variabel Disiplin terdapat dalam pernyataan no 3 dengan nilai rata-rata sebesar 3,63 dimana menyatakan bahwa kehadiran karyawan PT. Orchid Boga Utama sangat mempengaruhi kedisiplinan.. 
3. Diharapkan, manajemen PT. Orchid Boga Utama memberikan kesempatan bagi seluruh karyawan untuk mengikuti pelatihan kerja atau kesempatan pengembangan karir agar mampu meningkatkan hasil kerja karyawan karena nilai rata-rata jawaban terendah pada variabel Motivasi Kerja terdapat dalam pernyataan no 5 dengan skor rata-rata sebesar 3,73 dimana menyatakan bahwa pimpinan PT. Orchid Boga Utama memberikan kesempatan kepada karyawan untuk mengembangkan ketrampilan dan kemampuan dalam bekerja.

4. Bagi peneliti selanjutnya dengan berbagai keterbatasan penelitian ini, diharapkan lebih mendalam mengkaji perihal pengaruh human relation, disiplin dan motivasi kerja terhadap kepuasan kerja karyawan agar hasilnya lebih akurat. Selain itu, peneliti selanjutnya juga diharapkan untuk mengkaji variabel-variabel lain mengingat koefisien determinasi yang dihasilkan sebesar $72,40 \%$ sedangkan $27,60 \%$ terdapat variabel lain yang tidak termasuk dalam model penelitian yang kemungkinan berpengaruh terhadap kepuasan kerja karyawan.

\section{Daftar Pustaka}

Astuti. 2017. Analisis Motivasi Kerja Karyawan dalam Upaya Meningkatkan Produktivitas Kerja Karyawan, Bandung.

Afifah, Nur. 2015. Pengaruh Human Relation (Hubungan Antar Manusia) dan Kondisi Lingkungan Fisik Terhadap Etos Kerja Karyawan Pada PT. Delta Merlin Sandang Tekstil I Sragen. Skirpsi. Surakarta: Manajemen. Universitas Muhammadiyah Surakarta.

Armansyah. 2016. Pengaruh Human Relation Dan Lingkungan Kerja Terhadap Disiplin Kerja Pegawai dinas Bina Marga Provinsi Lampung. Skripsi. Fakultas Ekonomi dan Bisnis Universitas Lampung.

Br Sianturi, Sandrina Oktiana. 2018. Pengaruh Motivasi Terhadap Kinerja Pada Karyawan Mentok Karier. Skripsi. Program studi Psikologi Universitas Sanata Dharma Yogyakarta.

David dan Sri Nova Sari. 2017. Pengaruh Disiplin Kerja, Stres Kerja Dan Lingkungan Kerja Non Fisik Terhadap Kepuasan Kerja Karyawan Di Oxy Family Reflexy And Facial Pekanbru. Vol. 5 No. 4.

D.S, Mauritz, Lumentut da L.O.H Dotulong. 2015 . Pengaruh Motivasi, Disiplin, Dan Lingkungan Kerja Terhadap Kepuasan Kerja Karyawan Pada PT. Bank Sulut Cabang Airmadidi.

Eduard, Nico Michael. 2015. Pengaruh Kompensasi Finansial Dan Non Finansial Terhadap Motivasi Kerja Customer Service Grapari Telkomsel Cabang Pemuda, Surabaya.

Gunawan, Muhraweni dan Rasyid. 2017. Pengaruh Lingkungan Kerja Fisik, Lingkungan Kerja Fisik Dan Komunikasi Terhadap Kepuasan Kerja Pegawai Di Bagian Umum Sekretariat Daerah Kabupaten Soppeng. Jurnal Mirai Management. Vol. 2 No.1.

Girsang Laura Bethesrida. 2018. Pengaruh Pelatihan Dan Penilaian Kinerja Terhadap Kepuasan Kerja Karyawan PT. MItra Pinasthika Mustika Rent. Jurnal Administrasi Bisnis. Vol. 61 No. 2 . Malang. 
Ifriana dan Febsri Susanti. 2019. Pengaruh Lingkungan Kerja dan disiplin Kerja Terhadap Kepuasan Kerja Karyawan Pada Kantor Samsat Painan. 26 Maret 2019.

Indrawan, I Gede Adi. 2018. Analisis Pengaruh Kepemimpinan Transformasional, Promosi Jabatan, Lingkungan Kerja Non Fisik Terhadap Kepuasan Kerja Karyawan PT. Kustodian Sentral Efek Indonesia. Jurnal Mandiri. Vol. 2 No. 2.

Lie, Tjiong Fei dan Hotlan Siagian. 2018. Pengaruh Kepuasan Kerja Terhadap Kinerja Karyawan Melalui Motivasi Kerja Pada CV. Union Event Planner. Vol. 6 No. 1. Surabaya.

Mustofa, Naim. 2018. Pengaruh Motivasi, Disiplin Kerja dan Lingkungan Kerja Terhadap Kepuasan Karyawan Di Apotik Sumber Anom Warujayeng Nganjuk. Simki- Economic. Vol. 02 No. 01.

Mustikawati. Ida dan Husnul Hotimah. 2016. Pengaruh Human Relation Terhadap Peningkatan Kinerja Pegawai Negeri Sipil Di Kantor Kecamatan Panti Kabupaten Jember. Majalan Ilmiah. Vol. 16 No. 1.

Manuputty, Valentin.2018. Analisis Pengaruh Tunjangan Kinerja Daerah (TKD), Human Relation Dan Budaya Organisasi Terhadap Kinerja Aparatur Sipil Negara Dinas Tenaga Kerja dan Transmigrasi Provinsi Maluku. Vol 6 No 2.

Manoppo Rivo. 2015. Pengaruh Disiplin Kerja, Motivasi Kerja Dan Pengembangan Karir Terhadap Kepuasan Kerja Pada TVRI Sulawesi Utara. Jurnal EMBA. Vol. 3 No. 3 Hal. 1220-1231.

Najib, Rini Oktaviani dan Ramlawati. 2018. Analisis Dampak Human Relation Dan Lingkungan Kerja Fisik Terhadap Etos Kerja Pegawai BPJS Kesehatan Cabang Makassar. Jurnal Manajemen Bisnis. Vol 5 No 2. Hlm 13-21.

Paramban, Sumiati. 2018. Pengaruh Disiplin Kerja Dan Kepuasan Kerja Terhadap Kinerja Pegawai. Skripsi. Program Studi Manajemen Fakultas Ekonomi dan Bisnis, Jakarta.

Puguh Suharso. 2010. Model Analisis Kuantitatif“TEV”. Jakarta : Indeks.

Riofita, Hendra. 2017. Pengaruh Motivasi Finansial Dan Non Finansial Terhadap Kinerja Karyawan Badan Pelayanan Perizinan Terpadu Provinsi Riau.

Rathmah, Husnul. 2019. Analisis Human Relation Dan Lingkungan Kerja Terhadap Etos Kerja Dalam Meningkatkna Kinerja Karyawan Pada PT. Tirta Investama DC Solo. Skripsi. Fakultas Ekonomi Dan Bisnis Islam. Surakarta.

Sulaefi. 2018. Pengaruh Disiplin, Motivasi, Budaya Organisasi dan Stres Terhadap Kepuasan Kerja Pendidik di Kabupaten Brebes. Jurnal Manajemen. Vol. 22 No. 02.

Salbiyah, Siti dan Budi Wahyu Mahardhika. 2017. Pengaruh Motivasi Kerja Terhadap Kinerja Tenaga Kependidikan Universitas Muhammadiyah Surabaya. Vol. 14 No. 2.

Safrina Emi. Pengaruh Disiplin, Kompensasi Dan Komunikasi Terhadap Kinerja Karyawan Dengan Kepuasan Kerja Sebagai Variabel Intervening Pada Stasiun Pengisian Bahan Bakar umum (SPBU) Di Kabupaten Bireuen. Jurnal Ekonomi dan Bisnis. Vol. 18 No. 2 , Agt 2017.

Supriyadi Moch. Fachri dan Sidik Priadana Bayu Indra Setia. 2017. Kompensasi Dan Disiplin Kerja Terhadap Kepuasan Kerja Karyawan Di Restoran Kampoeng Daun. Jurnal Riset Bisnis Dan Manajemen. Vol. 10 No. 2 Hal. 24-33. 
Tentama, Fatwa dan Desta Rizky Kusuma. 2017. Faktor-Faktor Yang Mempengaruhi Peningkatan Kualitas Kinerja Karyawan Di Perguruan Tinggi Islam. Prosiding Seminar Nasional seri 7.Yogyakarta.

Zahara, Rizki Novriyanti dan Hajan Hidayat. 2017. Pengaruh Kepuasan Dan Disiplin Kerja Terhadap Kinerja Karyawan Bank Di Kota Batam. Journal Of Applied Managerial Accounting. Vol. 1 No 2. Hlm 150-156. 